\title{
Fulminant Guillain Barre syndrome with recurrent lung collapse
}

\author{
Hasif Kolleri, Mohammed Fardan, A. Priya, K. Arun Chander*
}

Department of Clinical Pharmacology, Apollo Children Hospital, Chennai, Tamil Nadu, India

Received: 21 October 2020

Accepted: 30 November 2020

*Correspondence:

Dr. K. Arun Chander,

Email: clinicalpharmaach_cni@apollohospitals.com

Copyright: (C) the author(s), publisher and licensee Medip Academy. This is an open-access article distributed under the terms of the Creative Commons Attribution Non-Commercial License, which permits unrestricted non-commercial use, distribution, and reproduction in any medium, provided the original work is properly cited.

\begin{abstract}
Fulminant Guillain-Barré syndrome (GBS) is a rapidly progressive form of polyneuropathy in which patients demonstrate eventual flaccid quadriplegia and an absence of brainstem function. Most patients present initially with a mild upper respiratory or gastrointestinal illness and have non-diagnostic cerebral imaging studies. Here we report the case of child aged 7 who was admitted initially with complaints of weakness of lower limbs lasting for 4-5 hours. He had difficulty in standing and walking, associated with pain in both lower limbs. Flaccid weakness rapidly progressed over 12 hours to involve both upper limbs along with difficulty in swallowing and nasal regurgitation of feeds. He was intubated and mechanically ventilated for respiratory failure. Over the period of time, after confirmation with all the test reports and symptoms, other differential diagnoses were ruled out and fulminant GBS was considered and hence plasmapheresis was started. Over the period of 3 months his muscle power slowly improved. During discharge, he was able to lift limbs against minimal resistance, turn sideways on bed, sit up with minimal support and likewise stand with support.
\end{abstract}

Keywords: Polyneuropathy, Flaccid weakness, Respiratory failure

\section{INTRODUCTION}

Guillain-Barré syndrome (GBS) is a peripheral nervous system disorder that presents as a rapidly progressive, ascending, flaccid paralysis with diminished or absent reflexes. The disease is often triggered by an infectious process, and it affects children of all ages. Once considered a single disease; many subtypes have been identified based on the neuronal components involved. ${ }^{1}$ It is the most common cause of acute weakness in patients under 40 years of age. $^{2}$ Respiratory compromise in GBS is connected to numerous factors. Upper airway route bargain and shortcoming of pharyngeal and laryngeal muscles lead to trouble in freeing from emissions and aviation route maintenance, in this manner likewise expanding the chance of aspiration. Guillain-Barre syndrome often commences with tingling and weakness beginning from the lower body and spreading to your upper body and arms. Notably, in about $10 \%$ of people with this disorder, symptoms begin in the arms or face. As Guillain-Barre syndrome progresses, muscle weakness can evolve into paralysis. ${ }^{3}$

Treatment of GBS usually combines multidisciplinary supportive medical care and immunotherapy. Proven effective treatments for GBS are IVIg and plasma exchange. ${ }^{4,5}$ Immunotherapy is usually started if patients are not able to walk 10 m unaided. ${ }^{6}$

\section{CASE REPORT}

The male child was presented with acute onset, rapidly progressive ascending flaccid paralysis. He was intubated for respiratory failure, mechanically ventilated and had received $2 \mathrm{~g} / \mathrm{kg}$ IVIg for suspected Guillain-Barre syndrome. His cerebrospinal fluid (CSF) analysis was 
essentially normal. On arrival, child had altered sensorium (GCS E1VtM1), equally reacting $3 \mathrm{~mm}$ pupils on both sides, absent DEM, absent gag/cough reflexes along with areflexic flaccid paralysis (power $0 / 5$ in all limbs). Emergency plain computed tomography (CT) brain revealed severe cerebral edema. In view of areflexic flaccid quadriplegia with altered sensorium; Bickerstaff brainstem encephalitis, Fulminant GBS and Acute demyelinating encephalomyeltis (ADEM) were considered as initial differential diagnosis. Since he had features of raised ICT with severe cerebral edema, neuroprotective measures were initiated along with ICP monitoring. Continuous Electroencephalogram (EEG) monitoring was done which showed slow waves with some sharp waves. Neurologist opinion was obtained and he was treated with Methyl prednisolone pulse therapy and empirical broad spectrum antibiotics along with Aciclovir. Since he had bilateral ophthalmoplegia and other cranial nerves involvement with no significant response to IVIg and pulse methyl prednisolone, Myasthenic crisis was considered and Neositigmine was initiated and pending confirmatory test results were awaited. Still, there was no improvement seemed with Neostigmine and moreover AntiAcetylcholine receptor (IgG) read negative, hence Neostigmine was stopped after a few doses. Ongoing antibiotics were stopped after 2 days since his first line blood investigations were unremarkable and initial CSF analysis was not suggestive of meningoencephalitis.

Magnetic resonance imaging (MRI) Brain with spine and nerve conduction study were done after initial stabilisation and management of intracranial hypertension which was suggestive of acute hemorrhagic leukoencephalitis. Whole spine screening was normal. Nerve conduction study was consistent with bilateral acute motor axonal neuropathy.

CSF analysis was repeated 1 week after the onset of illness, which showed sugar 99, protein 39.6, red blood cells (RBCs) 100, no white blood cells (WBCs), gram stain negative, meningoencephalitis panel (Filmarray) negative. CSF Ganglioside GM1, GM 2, GM3, GD1a, GD1b, GT1b, GQ1b IgG antibodies were negative (Sampling done after 2 doses of IVIg). Serum Mycoplasma pneumonia IgM was positive. Though its etiological significance was unknown, he was treated with injection Azithromycin for 7 days. Lymes's disease serology was negative. Vitamin B12 and vitamin D levels were normal.

Though his sensorium improved over 4-5 days, he had persistent areflexic flaccid quadriplegia (power $0 / 5$ in all limbs). After a team discussion including a second neurologist and other diagnoses having been ruled out, he was finally considered to have Fulminant GBS and was initiated on plasmapheresis, receiving 7 cycles in total.

His extra ocular and jaw movements improved, though his limb power remained 0/5. He had severe autonomic dysfunction with widely fluctuating heart rate and hypertension. He needed escalating doses of propranolol along with addition a titration of clonidine and nifedipine.
His muscle power slowly improved over 3 months. At discharge, he was able to lift limbs against minimal resistance, turn sideways on bed, sit up with minimal support and stand with support.

\section{DISCUSSION}

GBS represents an important acquired condition that is acutely evolving, is immune mediated, and an inflammatory disorder of the peripheral nervous system. It progresses rapidly leading to demyelination and axonal loss. Clinical hallmarks are symmetrical flaccid muscle paresis and areflexia in the presence of increased cerebrospinal fluid protein content and electrophysiologic studies demonstrating the evolvement of demyelination. ${ }^{6}$

Most patients develop a weakness which tends to begin in the lower extremities due to demyelination of the peripheral nerves resulting in ascending paralysis and also a loss of cranial nerve function. ${ }^{7}$ Manifestations may be acute or chronic, and temporary or permanent, depending upon the degree of neuronal destruction. ${ }^{8}$ Muscle stretch reflexes are depressed in most patients and the sensory loss is variable. Difficulty with walking, running, climbing stairs, and getting up from a chair are usual early complaints. This weakness is usually symmetric and can also involve the upper extremities. ${ }^{9}$ Similarly, here the patients had complaints of weakness of lower limbs for 45 hours. He had difficulty in standing and walking, associated with pain in both lower limbs. Flaccid weakness rapidly progressed over 12 hours to involve both upper limbs.

A patient with GBS needs multidisciplinary strong consideration to forestall or to deal with these different complexities and to encourage convenient exchange to the emergency unit when indicated. ${ }^{10}$ Need special consideration for prophylaxis against deep vein thrombosis (DVT), cardiovascular and hemodynamic monitoring, pain management, management of possible bladder and bowel dysfunction, physiotherapy, rehabilitation and psychosocial support. ${ }^{11}$ In this case; he was given limb physiotherapy along with orthotic splints and braces to prevent contractures. He was put on low molecular weight heparin and compression stockings for DVT prophylaxis. Adequate calorie and protein intake was ensured through nasogastric feeding along with micronutrient supplementation. Visual and auditory stimulation were given for early recovery with gradual improvement in power of limbs and mobilization.

In GBD, hospitalization is necessary for supportive care along with close monitoring for respiratory function and marked signs of dysautonomy. Intravenous immunoglobulin (IVIg therapy) and plasma exchange have been shown to be effective in such cases. Here, in this case patient's outcome was not remarkable even after administration of IVIg and steroid therapy (here, methylprednisolone pulse therapy); hence patient 
underwent plasmapheresis (7 cycles in total) which yielded promising results.

Overall, it is important to quickly diagnose GBS before it becomes fulminant, early ruling out differential diagnoses and start of definite treatment is necessary to slow down the progression and reduce the duration of the illness.

\section{CONCLUSION}

It is critical to recognize and earnestly refer; potential severe cases so as to have the proper examination (for example electro analytic investigations, spinal tap) found and have the fitting consideration. Differential conclusion is of most extreme significance. The recovery period for Guillain-Barré can be long, but most people recover. In general, symptoms will get worse for two to four weeks before they stabilize. Recovery can then take anywhere from a few weeks to a few years, but most recover in 6 to 12 months. Majority of population i.e., around 80 percent of people affected by Guillain-Barré can able to walk independently at six months, and 60 percent recover their regular muscle strength in one year. This case report shows that timely diagnosis and timely treatment approach, followed by proper supportive care allowed the patient to regain muscle power significantly. At the time of discharge, he was able to perform minimal day to day activities without any support.

\section{ACKNOWLEDGEMENTS}

We would like to express our immense gratitude towards the department of pediatric intensive care unit for helping us with all the data's necessary to assimilate together in this case report.

Funding: No funding sources Conflict of interest: None declared

Ethical approval: Not required

\section{REFERENCES}

1. Chung A, Deimling M. Guillain-Barre Syndrome. Pediatrics in Review. 2018;39(1):53-4.

2. Kraft GH, Freal JE, Coryell JK. Disability, disease duration and rehabilitation service needs in multiple sclerosis: patient perspectives. Arch Phys Med Rehabil. 1986;67(3):164-8.

3. Hughes RAC, Swan AV, Raphaël JC, Annane D, Koningsveld, Doorn PA, et al. Immunotherapy for Guillain Barre Syndrome: a systemic review. Brain. 2007;130:2245-57.

4. Hugesh RA, Swan AV, Van Doorn PA. Intravenous immunoglobulin for Guillain-Barre syndrome. Cochrane Database Syst Rev. 2014(9):CD002063.

5. Raphael JC, Chevret S, Hughes RA, Annane D. Plasma exchange for Guillain Barre Syndrome. Cochrane Database Syst Rev. 2012;11(7):CD001798.

6. Hund EF, Borel CO, Cornblath DR, Hanley DF, McKhann GM. Intensive management and treatment of severe Guillain-Barre syndrome. Crit. Care Med. 1993;21:433-46.

7. Ormerod IE, Ceekerell OC. Guillain-Barre syndrome after herpes zoster infection: a report of 2 cases. Eur Neurol. 1993;33(2):156-8.

8. Miller RG. Guillain Barre syndrome. Postgraduate Medicine. 1985;77(7):57-64.

9. Murray DP. Impaired mobility: Guillain-Barre syndrome. J Neurosci Nurs. 1993;25(2):100-4.

10. Hughes RAC, Wijdicks EFM, Benson E, Cornblath DR, Hahn AF, Meythaler JM, et al. Supportive care for patients with Guillain-Barre syndrome. Arch Neurol. 2005;62(8):1194-8.

11. Van Doorn P.A, Ruts L, Jacobs B.C. Clinical features, pathogenesis, and treatment of Guillain-Barre syndrome. The Lancet. Neurology 2008;7(10):939-50.

Cite this article as: Kolleri H, Fardan M, Priya A, Chander KA. Fulminant Guillain Barre syndrome with recurrent lung collapse. Int J Basic Clin Pharmacol 2021;10:127-9. 